This item was submitted to Loughborough's Research Repository by the author.

Items in Figshare are protected by copyright, with all rights reserved, unless otherwise indicated.

\title{
Inattention in very preterm children: implications for screening and detection
}

PLEASE CITE THE PUBLISHED VERSION

http://dx.doi.org/10.1136/archdischild-2013-305532

\section{PUBLISHER}

BMJ Publishing Group $@$ the authors

\section{VERSION}

AM (Accepted Manuscript)

\section{PUBLISHER STATEMENT}

This work is made available according to the conditions of the Creative Commons Attribution-NonCommercialNoDerivatives 4.0 International (CC BY-NC-ND 4.0) licence. Full details of this licence are available at: https://creativecommons.org/licenses/by-nc-nd/4.0/

\section{LICENCE}

CC BY-NC-ND 4.0

\section{REPOSITORY RECORD}

Brogan, Ellen, Lucy Cragg, Camilla K. Gilmore, Neil Marlow, Victoria Simms, and Samantha Johnson. 2019. "Inattention in Very Preterm Children: Implications for Screening and Detection". figshare.

https://hdl.handle.net/2134/16154. 


\section{Inattention in very preterm children: Implications for screening and detection}

Ellen Brogan ${ }^{1}$, BMBS, BMedSci (Hons); Lucy Cragg ${ }^{2}$, Ph.D, CPsychol; Camilla Gilmore ${ }^{3}$, Ph.D, CPsychol; Neil Marlow ${ }^{4}$, DM, FMedSci, Victoria Simms ${ }^{5}$, Ph.D, CPsychol; Samantha Johnson $^{5}$, Ph.D, CPsychol, AFBPsS.

Affiliations: ${ }^{1}$ Leicester Children's Hospital, University Hospitals of Leicester NHS Trust, Leicester, UK; ${ }^{2}$ School of Psychology, University of Nottingham, Nottingham, UK; ${ }^{3}$ Mathematics Education Centre, Loughborough University, Loughborough, UK; ${ }^{4}$ Research Department of Academic Neonatology, Institute for Women's Health, University College London, London, UK; ${ }^{5}$ Department of Health Sciences, University of Leicester, Leicester, UK.

Address Correspondence to: Dr Samantha Johnson, Department of Health Sciences, University of Leicester, 22-28 Princess Road West, Leicester, LE1 6TP, Email: sjj19@1e.ac.uk, Tel: +44 (0)116 252 5444, Fax: +44 (0)116252 3272.

Short title: ADHD symptoms in very preterm children

Keywords: Preterm birth; mental health; inattention; behaviour problems; special educational needs.

Abbreviations: ADHD - Attention Deficit/Hyperactivity Disorders; ASD - Autism Spectrum Disorders; IMD - Index of Multiple Deprivation; SEN - Special Educational Needs; SDQ Strengths and Difficulties Questionnaire.

Conflict of interest statement: No conflicts of interest to disclose. 


\section{Abstract}

Objective. Children born very preterm (VP; $<32$ weeks) are at risk for Attention Deficit/Hyperactivity Disorders (ADHD). ADHD in VP children has a different clinical presentation to ADHD in the general population, and therefore VP children with difficulties may not come to the teacher's attention in school. We have assessed ADHD symptoms to determine whether VP children's difficulties may go undetected in the classroom.

Design. Parents and teachers of 117 VP and 77 term-born children completed the Strengths and Difficulties Questionnaire (SDQ) to assess hyperactivity/inattention, emotional, conduct, and peer problems and the Du Paul ADHD Rating Scale-IV to assess inattention and hyperactivity/impulsivity symptoms. Special Educational Needs (SEN) were assessed using teacher report. Group differences in outcomes were adjusted for socio-economic deprivation. Results. Parents and teachers rated VP children with significantly higher SDQ hyperactivity/inattention scores, and parents rated them with more clinically significant hyperactivity/inattention difficulties than term-born controls (RR 4.0; 95\%CI 1.4, 11.4). Examining ADHD dimensions, parents and teachers rated VP children with significantly more inattention symptoms than controls and parents rated them with more clinically significant inattention (RR 4.8; 95\%CI 1.4, 16.0); in contrast, there was no excess of hyperactivity/impulsivity. After excluding children with SEN, VP children still had significantly higher inattention scores than controls but there was no excess of hyperactivity/impulsivity.

Conclusions. VP children are at greater risk for symptoms of inattention than hyperactivity/impulsivity. Inattention was significantly increased among VP children without identified SEN suggesting that these problems may be difficult to detect in school. Raising teachers' awareness of inattention problems may be advantageous in enabling them to identify very preterm children who may benefit from intervention. 
Very preterm ( $<32$ weeks) birth is associated with an increased risk of a cluster of mental health disorders, namely Anxiety Disorders, Autism Spectrum Disorders (ASD) and Attention Deficit/Hyperactivity Disorders (ADHD).(1) ADHD and attention problems are the most common adverse behavioural outcomes following very preterm birth(2-6). Even in the absence of diagnoses there is a generally higher level of attention difficulties amongst children born preterm; this results in a substantial number with symptoms that fall below the diagnostic threshold yet which may impact on daily activities and performance at school(7-9). In particular, a number of studies have reported a higher risk for inattention than hyperactivity/impulsivity, for both symptoms and diagnoses $(3,4,7,9,10)$, and a lack of comorbid conduct disorders among very preterm children $(2-4,6)$. These findings are suggestive of a core deficit in inattention in preterm populations.

Behaviour problems are associated with poor school performance and inattention in particular is a key predictor of academic attainment(9). It is thus unsurprising that very preterm children have poorer academic attainment than term-born peers and an increased prevalence of Special Educational Needs $(\mathrm{SEN})(11,12)$. The clinical presentation of ADHD associated with preterm birth also has specific implications for the classroom. Given the lack of comorbid conduct disorders, very preterm children may not come to the teacher's attention as having behavioural difficulites as readily as other children with ADHD who are hyperactive or disruptive in the classroom. Whilst children with hyperactivity/impulsivity may be identified as having SEN, those with 'purer' inattention problems may therefore go undetected in school.

The aims of this study were to assess the behavioural outcomes of very preterm children and to explore the relative impact of very preterm birth on symptoms of inattention versus 
hyperactivity/impulsivity. We hypothesised that very preterm children would have significantly higher levels of inattention than hyperactivity/impulsivity and that there would be a significant excess of inattention among very preterm children who are not identified with SEN.

\section{Participants and methods}

\section{Participants}

Very preterm children and term-born controls in mainstream schools aged 8-10 years were invited to participate in the Premature Infants' Skills in Mathematics (PRISM) study, a multicentre study of educational and behavioural outcomes following very preterm birth. All children born very preterm ( $<32$ weeks) from September 2001 through August 2003 and admitted for neonatal intensive care in two centres (University Hospitals of Leicester \& University College Hospital London, UK) were invited to participate. A term-born control group was also recruited. For each very preterm child, three classmates closest in age and of the same sex were identified from which one was selected at random using established procedures(12). Controls born $<37^{+0}$ weeks were excluded and a control child was not recruited where assessments were conducted at home rather than school, resulting in fewer controls than preterm children. Most children recruited to the study still lived in London and the East Midlands and all attended mainstream schools in England. Parents and children received a study information sheet and parents provided written consent. The study was approved by Derbyshire NHS Research Ethics Committee.

\section{Measures}

Parents and teachers were asked to complete study questionnaires. Children were in mainstream primary schools and therefore their main class teacher was asked to complete the 
questionnaire to ensure familiarity with the child's behaviour in the classroom. Both respondents completed the Strengths and Difficulties Questionnaire (SDQ)(13), a 25-item questionnaire to screen for behavioural and emotional disorders. The SDQ yields sub-scale scores (range 0-10) for four problem domains that assess emotional difficulties, conduct problems, peer relationship difficulties and hyperactivity/inattention. An additional 5-item supplement was also used to assess the impact of problems on the child's daily life comprising impact on home life, friendships, learning and leisure activities. Scores for the four problem domains were combined to give a total difficulties score (range 0-40); higher scores indicate greater difficulties. Scores were compared to cut-off scores for classifying children with clinically significant difficulties (abnormal screens) corresponding with scores $>90^{\text {th }}$ percentile in the standardisation sample $(13,14)$.

As SDQ hyperactivity/inattention scores are a composite score reflecting problems on both dimensions, symptoms of inattention and hyperactivity/impulsivity corresponding with ADHD diagnostic criteria were further explored using the Du Paul ADHD Rating ScaleIV(15), completed by parents and teachers. Raw scores were summed for each dimension with higher scores indicating greater difficulties. Age- and gender-specific percentile scores were also derived using published norms $(15)$ from which scores $>90$ th percentile were used to identify children with difficulties on each dimension to correspond with SDQ cut-offs.

Children in England are identified as having SEN if they have a 'learning difficulty which calls for special educational provision'(16). Information about SEN was obtained using teacher questionnaires. Information obtained via parent report was used to classify mothers' highest educational qualification and socio-occupational status using the National Statistics Socio-Economic Classification(17). National Statistics Index of Multiple Deprivation 
(IMD)(18) ranks were also derived using current postcode of residence and were used to determine whether each child lived in the least, middle, or most deprived areas of England.

\section{Statistical Analyses}

Data were double entered into two IBM SPSS Statistics v20 databases. These databases were compared and all discrepancies were verified with the original study records to ensure the accuracy of entered data. Study data were then analysed using IBM SPSS Statistics v20. Between group differences in continuous variables were analysed using linear regression with effect sizes reported as mean differences with $95 \%$ confidence intervals (95\% CI). To assess group differences in the proportion of children with abnormal screens, Poisson regressions with robust confidence intervals were used with effect sizes reported as Relative Risk (RR) with $95 \%$ CI. Given the marginally significant $(p=0.06)$ association of socio-economic deprivation with group membership, all between group comparisons were adjusted for deprivation using multivariable analyses with IMD tertile entered as a covariate. Unadjusted results are presented in Appendix A and B. All p-values were 2-tailed.

\section{Results}

Study sample

Of the whole very preterm population $(n=266)$, parents of 125 children responded to invitations to participate in the PRISM Study. As this study required children to participate in standardised tests of cognitive and educational attainment, 8 children were excluded ( 2 lived abroad, 3 attended special school and 3 had severe disability precluding them from participating in study tests) and 117 (44\%) were recruited. Teacher questionnaires were returned for $98(84 \%)$ children and parent questionnaires for $101(86 \%)$; at least one questionnaire was returned for $112(95 \%)$ children. There were no significant differences 
between very preterm children recruited and not recruited in birthweight (mean difference $6 \mathrm{~g} ; 95 \% \mathrm{CI}-105 \mathrm{~g}$ to $93 \mathrm{~g}, \mathrm{p}=0.90)$ or gestational age $(-0.2$ weeks, -0.1 to $0.3, \mathrm{p}=0.50)$, and there was no association between recruitment and IMD group $\left(\chi^{2}=3.62, p=0.16\right)$. Thus the sample recruited were representative of the total population in terms of key variables influencing long-term outcomes.

As described above, one randomly selected classmate for each very preterm child was invited to participate in the study. In total, 78 control children were recruited, of which one was later excluded due to preterm birth. The full sample thus comprised 77 term-born controls. Teacher questionnaires were returned for $72(94 \%)$ and parent questionnaires for 66 (86\%) children; at least one questionnaire was returned for $76(99 \%)$ children. Characteristics of very preterm children and controls for whom questionnaires were obtained are shown in Table 1. Given the marginally significant difference in socio-economic deprivation between the groups, all analyses were adjusted for IMD group.

\section{TABLE 1}

\section{Prevalence of behaviour problems}

After adjustment for socio-economic deprivation, parents rated very preterm children with significantly higher mean scores than controls for conduct problems, hyperactivity/inattention and total difficulties. Teachers rated very preterm children with significantly higher emotional, hyperactivity/inattention problems and total difficulties. Teachers also rated very preterm children with higher impact scores indicating a greater frequency of problems that affected very preterm children's daily activities (Table 2). Using published cut-offs for identifying children with clinically significant difficulties, parents rated very preterm children with 4 times increased risk for hyperactivity/inattention problems, but teacher ratings were not 
significantly different from controls. There was no significant difference in other domains as rated by parents and teachers, but both respondents rated preterm children with problems that had a significantly greater impact on their daily life (Table 2).

\section{TABLE 2}

\section{ADHD symptoms}

Both parents and teachers rated very preterm children with significantly higher mean inattention scores than controls with a difference of 3 points. In contrast, neither parents nor teachers rated very preterm children with a significant excess of hyperactivity/impulsivity symptoms (Table 2; Figure 1a). Repeated measures t-tests were used to explore the difference in inattention and hyperactivity/impulsivity ratings within both groups. Among very preterm children, both parents (mean difference $2.57,95 \%$ CI 1.77 to $3.37, \mathrm{p}<0.001$ ) and teachers $(3.91,2.75$ to $5.09, \mathrm{p}<0.001)$ rated them with significantly higher inattention than hyperactivity/impulsivity. In contrast, there was no significant difference in parents' ratings of inattention vs. hyperactivity/impulsivity among control children; teachers reported significantly higher scores for inattention than hyperactivity/impulsivity among controls $(0.97,0.24$ to $1.70, p=0.010)$, but this difference was significantly smaller than for VP children (i.e. no overlap in confidence intervals). To further explore interaction effects, difference scores (inattention minus hyperactivity/impulsivity) were calculated for each child for both parent and teacher ratings. Using linear regression with difference scores as a dependent variable, group was a significant predictor for both parent $(\mathrm{p}=0.009)$ and teacher reports $(\mathrm{p}<0.001)$, with VP children displaying significantly larger mean difference scores than control children for both parent (VP: Mean 1.92, SD 3.45; Control: Mean 0.40, SD 3.42) and teacher ratings (VP: Mean 1.91, SD 3.27; Control: Mean 0.36, SD 2.11). Using scores 
$>90^{\text {th }}$ percentile, parents rated very preterm children with almost 5 times increased risk for clinically significant inattention problems but there was no significant excess of hyperactivity/impulsivity; teachers ratings were not significantly different between groups (Table 2).

\section{FIGURE 1}

Behaviour problems in children without identified SEN

Overall, $41(42 \%)$ very preterm children and $13(18.3 \%)$ controls had identified SEN (adjusted RR 2.3, 95\% CI 1.3 to 3.9, $\mathrm{p}=0.003$ ). When children with SEN were excluded from the analyses, parents still rated very preterm children with significantly higher SDQ conduct problems and hyperactivity/inattention scores than controls, and teachers rated them only with significantly higher hyperactivity/inattention. As children with SEN were excluded, we did not find an excess of clinically significant problems as expected (Table 3).

\section{TABLE 3}

ADHD symptoms in children without identified SEN

After excluding children with SEN, very preterm children still had significantly higher inattention scores than controls as rated by both parents and teachers; in contrast, there was no significant excess of hyperactivity/impulsivity in either parent or teacher ratings (Table 3, Figure 1b). There was no excess of clinically significant ADHD symptoms once children with SEN were excluded from the analyses. 


\section{Discussion}

This study advances our understanding of the nature of ADHD symptoms among children born very preterm and provides further evidence that these are associated with a core deficit in inattention. Commensurate with previous studies, hyperactivity/inattention problems were most consistently elevated among very preterm children.(3, 5, 19) Although respondents differed in their ratings of emotional symptoms and conduct problems, both parents and teachers rated very preterm children with signficiantly higher hyperactivity/inattention scores than controls; parents also rated them with a 4-fold increased risk of clinically significant difficulties in this domain. In terms of risk ratios these results are similar to those of previous studies(1).

The SDQ hyperactivity/impulsivity scale assesses problems associated with both hyperactivity/impulsivity ( 3 items) and inattention ( 2 items). Scores may therefore reflect an excess of symptoms on either dimension, potentially masking differences in the profile of symptoms among clinical populations. Previous studies of extremely preterm children $(<26$ weeks) or those born with extremely low birthweight have indicated that ADHD among preterm children may be associated with a specific risk for inattention in terms of both symptoms and disorders $(3,4,7,9)$. Using a more detailed analysis of ADHD symptoms along separable dimensions we found that very preterm children had signifcantly higher inattention than hyperactivity/impulsivity scores and, compared with term-born controls, were at increased risk only for inattention symptoms. Our results thus provide further evidence that inattention is a core deficit among this population.

In addition to these findings, it is becoming increasingly evident that ADHD symptoms and disorders are rarely associated with comorbid conduct disorders among children born very 
preterm(4). Thus, unlike children in the general population with ADHD or other externalising behaviours, very preterm children are less likely to be disruptive in school and may be less likely to come to the teacher's attention as having difficulties. In fact, we have shown that even after excluding children with identified SEN in school, very preterm children still had significantly higher SDQ hyperactivity/inattention scores than term-born peers. Scores on the ADHD rating scale showed this increase was specific to inattention rather than hyperactivity/impulsivity.

Taken together these findings support our hypothesis that very preterm children with hyperactivity/impulsivity are more readily identified with SEN than those who have only inattention difficulties, and that an excess of inattention may still be present among those not receiving support in the classroom. This may reflect a general tendency for problems associated with preterm birth to go undetected in school. It has been argued that very preterm children are part of a growing generation of children with complex learning difficulties and disabilities that differ from those of previous generations and for which new approaches to screening and intervention are needed(20). It has been shown that teachers lack knowledge of the cognitive and behavioural outcomes and educational needs of children born preterm and that less than $10 \%$ feel they have received sufficient training in this area(21). This lack of knowledge may impact on teachers' awareness of the types of difficulties that very preterm children may present with and thus their ability to readily identify those children who have such problems in the classroom. Improving education professionals' awareness of the special constellation of cognitive and behavioural sequelae following preterm birth may therefore aid them in detecting inattention in the classroom and in providing appropriate support for very preterm children with these difficulties. 
A significant increase in SDQ scores among very preterm children without SEN is a notable finding because even 1-point increases in total difficulties scores are associated with an increased risk of psychiatric disorders(22). Moreover, the significant excess of inattention is concerning as this is a key predictor of long-term academic attainment(9). Inattention symptoms have been associated with poor working memory in very preterm children $(23,24)$, and inattention and working memory are important factors influencing academic attainment in both preterm and general population samples $(9,25,26)$. Routine screening for inattention in educational settings may therefore help in targeting the provision of SEN support and in identifying very preterm children with subtle, sub-clinical difficulties. The results of this study are thus useful for informing policy for screening and referral in this population.

In total, parents' and teachers' rated $21 \%$ of very preterm children with abnormal total difficulties scores and $23 \%-24 \%$ of very preterm children with difficulties that impacted on their daily living. Our results are thus similar to the $\sim 25 \%$ prevalence of psychiatric disorders reported in various preterm populations $(1,27)$. Consistent with previous studies $(5,28,29)$, teachers generally rated children with fewer difficulties than parents. Teachers' views of children's behaviours may be influenced by the school environment and by a different perspective arising from the observation of greater numbers of children. Given the known effects of report source bias $(5,30)$, we solicited ratings from both parents and teachers to provide multi-informant data.

The strengths of this study lie in the recruitment of a sample of very preterm children who were representative of the whole population. We used a validated rating scale to explore ADHD symptoms along separable dimensions to allow a more detailed exploration of the nature of these difficulties among very preterm children. The $18.3 \%$ prevalence of SEN 
among the term-born controls is remarkably similar to the $18.8 \%$ prevalence of SEN in the general population (31), providing assurance that our control sample was representative of the general population in terms of academic and behavioural difficulties. Children with significant disabilities and those attending special schools were excluded, and therefore our findings may underestimate the true prevalence of behaviour problems and SEN in the very preterm population. Although the classification of SEN differs between education systems, there is cross-cultural consistency in behavioural outcomes across preterm and low birthweight populations(32). Thus, the potential for very preterm children with inattention to be missed in school is likely to be universal and warrants further investigation.

\section{Conclusion}

ADHD symptoms in very preterm children are associated with a core deficit in inattention. Given the constellation of behavioural outcomes following preterm birth, very preterm children with inattention may not be readily identified as having problems in the classroom. If such problems are undetected these may have a detrimental impact on very preterm children's learning and attainment at school. Enhancing teachers' awareness of the behavioural outcomes of this vulnerable population and screening for inattention may be beneficial in identifying very preterm children with subtle difficulties that may otherwise go undetected. 
Acknowledgements: We would like to thank the children, parents and teachers who took part in the Premature Infants' Skills in Mathematics (PRISM) Study (www.prismstudy.org.uk).

Funding source: This study was funded by an Action Medical Research project grant to Samantha Johnson, Camilla Gilmore, Lucy Cragg and Neil Marlow. Neil Marlow receives a proportion of funding from the Department of Health's NIHR Biomedical Research Centres funding scheme at UCLH/UCL. Camilla Gilmore is funded by a Royal Society Dorothy Hodgkin Fellowship.

\section{Authors contributions:}

1) Ellen Brogan contributed to data entry, analysis and interpretation, drafted the manuscript and approved the submitted version. 2) Lucy Cragg conceptualised and designed the study, revised the manuscript for intellectual content and approved the submitted version. 3) Camilla Gilmore conceptualised and designed the study, revised the manuscript for intellectual content and approved the submitted version. 4) Neil Marlow conceptualised and designed the study, revised the manuscript for intellectual content and approved the submitted version. 5) Victoria Simms acquired the data, contributed to data analysis and interpretation, revised the manuscript for intellectual content and approved the submitted version. 6) Samantha Johnson conceptualised and designed the study, revised the manuscript for intellectual content and approved the submitted version. 


\section{What is already known about this topic:}

- Children born very preterm are at increased risk for poor mental health outcomes, especially ADHD.

- It has been suggested that inattention is a core deficit among very preterm children with ADHD symptoms.

- Inattention is a key predictor of poor performance at school.

\section{What this study adds:}

- Very preterm children's ADHD symptoms are underscored by a core deficit in inattention.

- Among children without identified special educational needs, very preterm children had significantly higher levels of inattention than their term-born classmates.

- Raising teachers' awareness of inattention problems may enable them to identify very preterm children who may benefit from educational intervention. 


\section{References}

1. Johnson S, Marlow N. Preterm Birth and Childhood Psychiatric Disorders. Pediatric Research. 2011;69:11r-8r Online.

2. Treyvaud K, Ure A, Doyle LW, et al. Psychiatric outcomes at age seven for very preterm children: rates and predictors. Journal of child psychology and psychiatry, and allied disciplines. 2013;54:772-9 doi: 10.1111/jcpp.12040 [published Online First: 2013/01/26].

3. Hack M, Taylor HG, Schlichter M, Andreias L, Drotar D, Klein N. Behavioral outcomes of extremely low birth weight children at age 8 years. Journal of Developmental and Behavioral Pediatrics. 2009;30:122-30 Online.

4. Johnson S, Hollis C, Kochhar P, Hennessy E, Wolke D, Marlow N. Psychiatric Disorders in Extremely Preterm Children: Longitudinal Finding at Age 11 Years in the EPICure Study. Journal of the American Academy of Child \& Adolescent Psychiatry. 2010;49:453-63.e1 Online.

5. Bora S, Pritchard VE, Moor S, Austin NC, Woodward LJ. Emotional and behavioural adjustment of children born very preterm at early school age. $J$ Paediatr Child Health. 2011;47:863-9 doi: 10.1111/j.1440-1754.2011.02105.x [published Online First: 2011/06/18].

6. Botting N, Powls A, Cooke R, Marlow N. Attention Deficit Hyperactivity Disorder and other psychiatric outcomes in very low birthweight children at 12 years. Journal of Child Psychology and Psychiatry. 1997;38:931-41 Online.

7. Johnson S, Wolke D. Behavioural outcomes and psychopathology during adolescence. Early Hum Dev. 2013; doi: 10.1016/j.earlhumdev.2013.01.014 [published Online First: 2013/03/05].

8. Indredavik MS, Vik T, Heyerdahl S, Kulseng S, Fayers P, Brubakk AM. Psychiatric symptoms and disorders in adolescents with low birth weight. Archives of Disease in Childhood. 2004;89:F445-F50 doi: 10.1136/adc.2003.038943 [published Online.

9. Jaekel J, Wolke D, Bartmann P. Poor attention rather than hyperactivity/impulsivity predicts academic achievement in very preterm and fullterm adolescents. Psychol Med. 2012:1-14 doi: 10.1017/S0033291712001031 [published Online First: 2012/05/23].

10. Shum D, Neulinger K, O'Callaghan M, Mohay H. Attentional problems in children born with very preterm or with extremely low birth weight at 7-9 years. Archives of Clinical Neuropsychology. 2008;23:103-12 Online.

11. MacKay DF, Smith GC, Dobbie R, Pell JP. Gestational age at delivery and special educational need: retrospective cohort study of 407,503 schoolchildren. PLoS Med. 2010;7:e1000289 Online.

12. Johnson S, Hennessy E, Smith R, Trikic R, Wolke D, Marlow N. Academic attainment and special educational needs in extremely preterm children at 11 years. The EPICure Study. Archives of Disease in Childhood Fetal and Neonatal Edition. 2009;94:F283-F9 Online.

13. Goodman R, Ford T, Simmons H, Gatward R, Meltzer H. Using the Strengths and Difficulties Questionnaire (SDQ) to screen for child psychiatric disorders in a community sample. Br J Psychiatry. 2000;177:534-9 Online First: 2000/12/05].

14. Youthinmind. SDQ: Information for researchers and professionals about the Strengths \& Difficulties Questionnaires. London: Youthinmind 2013. Accessed 02/04/2014. 
15. DuPaul GJ, Power TJ, Anastopoulos AD, Reid R. ADHD Rating Scale-IV. New York: The Guilford Press; 1998.

16. Department for Education. Special Educational Needs Code of Practice. London2001.

17. Office for National Statistics. The National Statistics Socio-Economic Classification User Manual. Basingstoke: Palgrave Macmillan 2010.

18. Lad M. The English Indices of Deprivation 2010. London: Department for Communities and Local Government:London 2011.

19. Samara M, Marlow N, Wolke D. Pervasive Behavior Problems at 6 Years of Age in a Total-Population Sample of Children Born at $<=25$ Weeks of Gestation. Pediatrics. 2008;122:562-73 doi: 10.1542/peds.2007-3231 [published Online.

20. Specialist Schools and Academies Trust. Complex Learning Difficulties and Disabilities Research Project. 2013.

21. Henderson D, Beer C, wolke D, Johnson S. Supporting the schooling of very preterm children: Education professionals' opinions and information needs. . Archives Disease in Childhood 2012;97:A353 Online.

22. Goodman A, R G. Population mean scores predict child mental disorder rates: validating SDQ prevalence estimators in Britain. J Child Psychol Psychiatry 2011;52:100-8 Online.

23. Mulder H, Pitchford NJ, Marlow N. Inattentive behaviour is associated with poor working memory and slow processing speed in very pre-term children in middle childhood. The British journal of educational psychology. 2011;81:147-60 doi: 10.1348/000709910X505527 [published Online First: 2011/03/12].

24. Nadeau L, Boivin M, Tessier R, Lefebvre F, Robaey P. Mediators of behavioral problems in 7-year-old children born after 24 to 28 weeks of gestation. Developmental and Behavioral Pediatrics. 2001;22:1-10 Online.

25. Mulder H, Pitchford NJ, Marlow N. Processing speed and working memory underlie academic attainment in very preterm children. Archives of disease in childhood Fetal and neonatal edition. 2010;95:F267-72 doi:

10.1136/adc.2009.167965 [published Online First: 2010/05/22].

26. Bull R, Espy KA, Wiebe SA. Short-term memory, working memory, and executive functioning in preschoolers: longitudinal predictors of mathematical achievement at 7 years. Developmental Neuropsychology. 2008;33:205-28 Online. 27. Burnett AC, Anderson PJ, Cheong J, Doyle LW, Davey CG, Wood SJ. Prevalence of psychiatric diagnoses in preterm and full-term children, adolescents and young adults: A meta-analysis. Psychological Medicine. 2011;41:2463-74 doi: 10.1017/s003329171100081x [published Online.

28. Brown JD, Wissow LS, Gadomski A, Zachary C, Bartlett E, Horn I. Parent and teacher mental health ratings of children using primary-care services: interrater agreement and implications for mental health screening. Ambulatory pediatrics : the official journal of the Ambulatory Pediatric Association. 2006;6:347-51 doi: 10.1016/j.ambp.2006.09.004 [published Online First: 2006/11/23].

29. Dahl LB, Kaaresen PI, Tunby J, Handegard BH, Kvernmo S, Ronning JA. Emotional, behavioral, social, and academic outcomes in adolescents born with very low birth weight. Pediatrics. 2006;118:E449-E59 doi: 10.1524/peds.20053021 [published Online.

30. Johnson S, Hollis C, Marlow N, Simms V, Wolke D. Screening for childhood mental health disorders using the Strengths and Difficulties Questionnaire: the validity of multi-informant reports. Dev Med Child Neurol. 2014; doi: 10.1111/dmcn.12360 [published Online First: 2014/01/15]. 
31. Department for Education. Special Educational Needs in England. London: Department for Education 2013.

32. Farooqi A, Hagglof B, Sedin G, Gothefors L, Serenius F. Mental Health and Social Competencies of 10- to 12-Year-Old Children Born at 23 to 25 Weeks of Gestation in the 1990s: A Swedish National Prospective Follow-up Study. Pediatrics. 2007;120:118-33 Online. 


\section{Licence for publication statement}

The Corresponding Author has the right to grant on behalf of all authors and does grant on behalf of all authors, an exclusive licence (or non-exclusive for government employees) on a worldwide basis to the BMJ Group and co-owners or contracting owning societies (where published by the BMJ Group on their behalf), and its Licensees to permit this article (if accepted) to be published in Archives of Disease in Childhood and any other BMJ Group products and to exploit all subsidiary rights, as set out in our licence. 
Table 1. Characteristics of children and their mothers who participated in the study.

\begin{tabular}{|c|c|c|c|}
\hline Characteristic & $\begin{array}{c}\text { Controls } \\
n=76\end{array}$ & $\begin{array}{c}\text { Very Preterm } \\
\mathrm{n}=112\end{array}$ & $p$ \\
\hline Gestational age (weeks), median (IQR) & - & $28.6(1.9)$ & - \\
\hline Birthweight (g), mean (SD) & - & $1218(362)$ & - \\
\hline Male sex, n (\%) & $40(53 \%)$ & $62(55 \%)$ & 0.7 \\
\hline Age at assessment (years), mean (SD) & $9.5(0.7)$ & $9.7(0.7)$ & 0.09 \\
\hline Mothers age (years), mean (SD)* & $40.1(6.0)$ & $40.3(5.5)$ & 0.8 \\
\hline Index of Multiple Deprivation tertile**: & & & 0.06 \\
\hline High deprivation & $37(49 \%)$ & $43(37 \%)$ & \\
\hline Middle deprivation & $18(24 \%)$ & $20(18 \%)$ & \\
\hline Low deprivation & $20(27 \%)$ & $49(45 \%)$ & \\
\hline Socio-occupational class: & & & 0.6 \\
\hline Professional \& managerial & $25(33 \%)$ & $40(36 \%)$ & \\
\hline Intermediate \& technical & $27(36 \%)$ & $30(27 \%)$ & \\
\hline Routine and semi-routine & $6(8 \%)$ & $12(11 \%)$ & \\
\hline Never worked/ unemployed & $8(11 \%)$ & $18(16 \%)$ & \\
\hline Not known & $10(13 \%)$ & $12(11 \%)$ & \\
\hline Maternal highest level of education: & & & 0.8 \\
\hline Less than degree & $46(61 \%)$ & $72(64 \%)$ & \\
\hline Degree or higher & $20(26 \%)$ & $28(25 \%)$ & \\
\hline Not known & $10(13 \%)$ & $12(11 \%)$ & \\
\hline
\end{tabular}


Table 2: SDQ and ADHD Rating Scale scores for very preterm children and term-born controls adjusted for IMD tertile.

\begin{tabular}{|c|c|c|c|c|c|c|c|c|}
\hline Measure & $\begin{array}{c}\text { Control } \\
\text { Mean (SD) }\end{array}$ & $\begin{array}{c}\text { Very preterm } \\
\text { Mean (SD) }\end{array}$ & $\begin{array}{c}\text { Adjusted Mean } \\
\text { difference }(95 \% \mathrm{CI})^{\text {a }}\end{array}$ & $\mathbf{p}$ & $\begin{array}{c}\text { Control } \\
\text { n (\%) abnormal }\end{array}$ & $\begin{array}{l}\text { Very Preterm } \\
\text { n (\%) abnormal }\end{array}$ & Adjusted RR (95\% CI) & $\bar{p}$ \\
\hline \multicolumn{9}{|c|}{ Strengths and Difficulties Questionnaire: PARENT RATING (Control $n=65$; Very preterm $n=101$ ) } \\
\hline Emotional* & $1.9(2.2)$ & $2.3(2.4)$ & $0.3(-0.4$ to 1.1$)$ & 0.4 & $8(12 \%)$ & $20(20 \%)$ & $1.6(0.7$ to 3.6$)$ & 0.2 \\
\hline Conduct & $1.0(1.4)$ & $1.7(1.7)$ & $0.6(0.1$ to 1.1$)$ & $\mathbf{0 . 0 3}$ & $4(6 \%)$ & $12(12 \%)$ & $1.7(0.5$ to 5.3$)$ & 0.4 \\
\hline Peer & $1.2(1.5)$ & $1.7(2.1)$ & $0.4(-0.3$ to 1.0$)$ & 0.3 & $5(8 \%)$ & $16(16 \%)$ & $1.9(0.7$ to 5$)$ & 0.2 \\
\hline Hyperactivity/inattention & $2.7(2.4)$ & $4.3(2.9)$ & $1.5(0.6$ to 2.4$)$ & 0.001 & $4(6 \%)$ & $26(26 \%)$ & $4.0(1.4$ to 11.4$)$ & 0.009 \\
\hline Total difficulties* & $6.7(5.4)$ & $9.9(7.3)$ & $2.6(0.5$ to 4.7$)$ & 0.01 & $5(8 \%)$ & $16(16 \%)$ & $1.9(0.7$ to 5.2$)$ & 0.2 \\
\hline Impact** & $0.4(1.5)$ & $0.9(1.7)$ & $0.4(-0.1$ to 0.9$)$ & 0.1 & $5(8 \%)$ & $23(23 \%)$ & $2.8(1.1$ to 7.3$)$ & 0.03 \\
\hline \multicolumn{9}{|c|}{ Strengths and Difficulties Questionnaire: TEACHER RATING (Control $n=71$; Very preterm $n=97$ ) } \\
\hline Emotional & $1.2(1.7)$ & $2.0(2.4)$ & $0.7(0.0$ to 1.4$)$ & 0.04 & $2(3 \%)$ & $10(10 \%)$ & $3.5(0.8$ to 15.7$)$ & 0.06 \\
\hline Conduct & $0.5(1.1)$ & $0.6(1.1)$ & $0.1(-0.3$ to 0.4$)$ & 0.8 & $2(3 \%)$ & $3(3 \%)$ & $1.3(0.2$ to 8.7$)$ & 0.8 \\
\hline Peer & $0.9(1.2)$ & $1.4(2.1)$ & $0.4(-0.1$ to 1.0$)$ & 0.2 & $1(1 \%)$ & $10(10 \%)$ & $6.4(0.7$ to 52.7$)$ & 0.08 \\
\hline Hyperactivity/inattention & $2.0(2.8)$ & $3.2(2.6)$ & $1.0(0.2$ to 1.8$)$ & 0.02 & $8(11 \%)$ & $13(13 \%)$ & $1.1(0.5$ to 2.5$)$ & 0.9 \\
\hline Total difficulties & $4.7(4.8)$ & $7.2(6.0)$ & $2.2(0.5$ to 3.9$)$ & 0.01 & $2(3 \%)$ & $11(11 \%)$ & $3.5(0.8$ to 15.5$)$ & 0.09 \\
\hline Impact ${ }^{* * *}$ & $0.1(0.4)$ & $0.8(1.3)$ & $0.6(0.3$ to 1.0$)$ & $<0.001$ & $2(3 \%)$ & $22(24 \%)$ & $7.7(1.8$ to 32.1$)$ & 0.005 \\
\hline \multicolumn{9}{|c|}{ Du Paul ADHD Rating Scale IV: PARENT RATING (Control $n=65$; Very preterm $n=102$ ) } \\
\hline Inattention & $4.3(4.6)$ & $7.7(6.8)$ & $3.3(1.4$ to 5.3$)$ & 0.001 & $3(5 \%)$ & $23(23 \%)$ & $4.8(1.4$ to 16.0$)$ & 0.01 \\
\hline Hyperactivity & $3.4(4.0)$ & $5.1(5.5)$ & $1.6(-0.0$ to 3.2$)$ & 0.05 & $4(6 \%)$ & $12(12 \%)$ & $2.1(0.6$ to 6.9$)$ & 0.2 \\
\hline \multicolumn{9}{|c|}{ Du Paul ADHD Rating Scale IV: TEACHER RATING (Control n=71; Very preterm n=98) } \\
\hline Inattention & $3.0(4.7)$ & $6.6(6.8)$ & $3.2(1.3$ to 5.0$)$ & 0.001 & $0(0 \%)$ & $1(1 \%)$ & - & - \\
\hline Hyperactivity & $2.1(4.1)$ & $2.6(4.0)$ & $0.4(-0.9$ to 1.6$)$ & 0.6 & $2(3 \%)$ & $1(1 \%)$ & $0.4(0.0$ to 5.1$)$ & 0.5 \\
\hline
\end{tabular}

Bold $\mathrm{p}$ values denote significance at $\mathrm{p}<0.05$ level. *Very preterm $=100 ; * *$ Control $\mathrm{n}=64 ; * * *$ Control $=70$, Very preterm $=93$ 
Table 3: SDQ and ADHD Rating Scale scores for children without identified special educational needs adjusted for IMD tertile.

\begin{tabular}{|c|c|c|c|c|c|c|c|c|}
\hline & $\begin{array}{c}\text { Control } \\
\text { Mean (SD) }\end{array}$ & $\begin{array}{c}\text { Very Preterm } \\
\text { Mean (SD) }\end{array}$ & $\begin{array}{c}\text { Adjusted Mean difference } \\
(95 \% \mathrm{CI})^{\mathrm{a}}\end{array}$ & $\mathbf{p}$ & $\begin{array}{c}\text { Control } \\
\mathrm{n}(\%) \text { abnormal } \\
\end{array}$ & $\begin{array}{l}\text { Very Preterm } \\
\mathrm{n}(\%) \text { abnormal }\end{array}$ & Adjusted RR (95\% CI) ${ }^{\mathrm{a}}$ & $p$ \\
\hline \multicolumn{9}{|c|}{ Strengths and Difficulties Questionnaire: PARENT RATING (Control $n=52$; Very preterm $n=52$ ) } \\
\hline Emotional & $1.8(2.0)$ & $1.6(2.0)$ & $-0.3(-1.1$ to 0.5$)$ & 0.4 & $5(10 \%)$ & $6(12 \%)$ & $1.1(0.3$ to 3.5$)$ & 0.9 \\
\hline Conduct & $0.7(1.1)$ & $1.4(1.5)$ & $0.6(0.1$ to 1.1$)$ & 0.02 & $2(4 \%)$ & $5(10 \%)$ & $1.8(0.3$ to 9.6$)$ & 0.5 \\
\hline Peer & $1.1(1.3)$ & $1.0(1.5)$ & $-0.2(-0.7$ to 0.4$)$ & 0.5 & $3(6 \%)$ & $4(8 \%)$ & $1.3(0.3$ to 5.4$)$ & 0.7 \\
\hline Hyperactivity/inattention & $2.0(2.0)$ & $3.1(2.3)$ & $0.9(0.1$ to 1.8$)$ & $\mathbf{0 . 0 3}$ & $1(2 \%)$ & $5(10 \%)$ & $4.6(0.6$ to 34.8$)$ & 0.1 \\
\hline Total difficulties & $5.5(4.3)$ & $7.2(5.3)$ & $1.1(-0.8$ to 2.9$)$ & 0.2 & $2(4 \%)$ & $3(6 \%)$ & $1.2(0.2$ to 6.9$)$ & 0.9 \\
\hline Impact $^{*}$ & $0.1(0.5)$ & $0.3(0.9)$ & $0.1(-0.2$ to 0.4$)$ & 0.4 & $2(4 \%)$ & $5(10 \%)$ & $1.9(0.4$ to 8.9$)$ & 0.4 \\
\hline \multicolumn{9}{|c|}{ Strengths and Difficulties Questionnaire: TEACHER RATING (Control $n=57$; Very preterm $n=55$ ) } \\
\hline Emotional & $1.1(1.6)$ & $1.3(1.8)$ & $0.1(-0.6$ to 0.7$)$ & 0.8 & $2(4 \%)$ & $1(2 \%)$ & $0.4(0.0$ to 3.5$)$ & 0.4 \\
\hline Conduct & $0.4(0.9)$ & $0.5(1.1)$ & $0.1(-0.3$ to 0.5$)$ & 0.7 & $1(2 \%)$ & $2(4 \%)$ & $2.8(0.3$ to 27.7$)$ & 0.4 \\
\hline Peer & $0.8(1.2)$ & $0.8(1.7)$ & $-0.1(-0.7$ to 0.4$)$ & 0.7 & $1(2 \%)$ & $2(4 \%)$ & $1.3(0.4$ to 4.2$)$ & 0.7 \\
\hline Hyperactivity/inattention & $1.3(2.1)$ & $2.4(2.4)$ & $1.0(0.1$ to 1.9$)$ & 0.02 & $2(4 \%)$ & $5(9 \%)$ & $2.4(0.5$ to 10.7$)$ & 0.3 \\
\hline Total difficulties & $3.7(4.1)$ & $5.1(5.0)$ & $1.1(-0.7$ to 2.7$)$ & 0.2 & $1(2 \%)$ & $3(6 \%)$ & $2.8(0.4$ to 21.5$)$ & 0.3 \\
\hline Impact $^{* *}$ & $0.0(0.2)$ & $0.2(0.8)$ & $0.1(-0.1$ to 0.4$)$ & 0.2 & $0(5 \%)$ & $3(6 \%)$ & - & - \\
\hline \multicolumn{9}{|c|}{ Du Paul ADHD Rating Scale IV: PARENT RATING (Control $n=52$; Very preterm $n=52$ ) } \\
\hline Inattention & $3.2(3.8)$ & $4.9(5.0)$ & $1.8(0.5$ to 3.5$)$ & 0.04 & $1(2 \%)$ & $4(8 \%)$ & $4.6(0.6$ to 38.0$)$ & 0.2 \\
\hline Hyperactivity & $2.9(3.7)$ & $3.0(3.4)$ & $-0.0(-1.4$ to 1.4$)$ & 1.0 & $3(6 \%)$ & $2(4 \%)$ & $0.7(0.1$ to 5.0$)$ & 0.7 \\
\hline \multicolumn{9}{|c|}{ Du Paul ADHD Rating Scale IV: TEACHER RATING (Control $n=57$; Very preterm $n=56$ ) } \\
\hline Inattention & $1.7(3.2)$ & $3.9(4.6)$ & $1.9(0.4$ to 3.4$)$ & 0.01 & $0(0 \%)$ & $0(0 \%)$ & - & - \\
\hline Hyperactivity & $1.4(3.1)$ & $2.0(3.8)$ & $0.4(-0.9$ to 1.8$)$ & 0.5 & $2(4 \%)$ & $0(0 \%)$ & - & - \\
\hline
\end{tabular}

Bold $\mathrm{p}$ values denote significance at $\mathrm{p}<0.05$ level. ${ }^{*}$ Control $=51$, Very preterm $\mathrm{n}=51 ; * *$ Very preterm $=52$ 


\section{Figure caption}

Figure 1. Mean difference (95\% confidence interval) in z-scores for teacher- and parent-rated inattention and hyperactivity/impulsivity symptoms between very preterm children and termborn controls adjusted for socio-economic deprivation. Figure 1a shows data for all children. Figure $1 \mathrm{~b}$ shows data for children without identified special educational needs (SEN). Higher z-scores indicate a higher level of symptoms in each domain. 